\title{
Modeling for reorientation and potential of enhanced oil recovery in refracturing
}

\author{
Mingjing $\mathrm{Lu}^{1,2 \oplus *}$, Yuliang $\mathrm{Su}^{1}$, Shiyuan $\mathrm{Zhan}^{1}$, Abdulhadi Almrabat ${ }^{2}$ \\ ${ }^{1}$ School of Petroleum Engineering, China University of Petroleum (East China), Qingdao 266580, P. R. China \\ ${ }^{2}$ Department of Civil and Environmental Engineering, Colorado School of Mines, Golden CO 80401, USA
}

\section{Keywords:}

Refracturing

fracture reorientation

potential evaluation

residual oil distribution

enhanced oil recovery

Cited as:

Lu, M., Su, Y., Zhan, S., Almarbat, A. Modeling for reorientation and potential of enhanced oil recovery in refracturing. Advances in Geo-Energy Research, 2020, 4(1): 20-28, doi:

10.26804/ager.2020.01.03.

\begin{abstract}
:
Reorientation of fractures and high production improvement are observed and illustrated by fields and theoretical researches. During the refracturing treatments, it is important to get familiar with the enhanced oil recovery mechanics of fracture reorientation and distribution of residual oil. Mechanisms of fracture reorientation are discussed in order to design the parameters of reoriented fractures in numerical simulation. To furtherly evaluate the oil recovery of different angles of reoriented fractures, geological and numerical models are simulated using data of the actual reservoir with rhombus inverted nine spot well pattern, different angles of reoriented fracture are designed for both corner and edge wells to obtain the enhanced oil recovery. Results show that potential of production increase is highly impacted by the well pattern and angles of fractures and meanwhile impacted by distribution of residual oil and formation properties. Oil enhancement potential is significantly different with fracture reorientation angles in refracturing treatment: cumulative produced oil for corner wells is symmetrical around the angle of $0^{\circ}$ and reaches the highest at the angles of positive and negative $23^{\circ}$; for the edge wells, it is also symmetrical around the angle of $0^{\circ}$ while reaches the highest cumulative oil at the angles of positive and negative $90^{\circ}$. The difference shows that optimal angles exist for reoriented fractures during refracturing design and with proper induced reoriented fractures, more oil will be recovered for field restimulation treatments.
\end{abstract}

\section{Introduction}

Well production will decrease due to lose of flow conductivity in the initial fractures after fracturing treatment (Sallee and Rugg, 1953; Hubbert and Willis, 1972). Refracturing treatment is one of the most effective restimulation technique to regain or enhance production in those wells after long-term development, it is announced that the estimated ultimate recovery (EUR) could be increased by $53 \%$ in the Eagleford and by $69 \%$ in the Bakken after refracturing treatment (Preiksaitis et al., 2016; Shah et al., 2017). There are three main purposes of refracturing treatment in order to increase the EUR, reopening the initial fractures and injecting more proppant to restore the flow capacity, improving the fracture geometry of the initial fractures to reach far field residual oil, and inducing fracture reorientation to connect the by-passed pay zones in reservoirs (Elbel and Mack, 1993; Vincent, 2011).
Oil recovery will be boosted if fractures are reoriented in refracturing treatment since more residual oil will be mobilized and high pressure region will be intersected. After being monitored in field tests, fracture reorientation has been a research hotspot due to its high production enhancement. In situ stress field alternation is the main reason that leads to fracture reorientation in refracturing treatment (Warpinski and Branagan, 1989; Zhang and Chen, 2010; Roussel and Sharma, 2012). New fractures will initiate and propagate to the perpendicular direction of the initial fractures which is observed in both vertical wells (Siebrits et al., 1998; Roussel and Sharma, 2010) and horizontal wells (Roussel and Sharma, 2011; Barree et al., 2017). In water flooding reservoirs, water injection and underground liquid withdrawn will lead to pressure gradient of formation and then impact the in situ stress field (Berchenko and Detournay, 1997). Stress reversal region will be formed with stress field alternation and

* Corresponding author.

E-mail address: lumingjing001@126.com (M. Lu); suyuliang@upc.edu.cn (Y. Su); 1207842779@qq.com (S. Zhan);

abdulhadi18@gmail.com (A. Almrabat).

2207-9963 (c) The Author(s) 2020.

Received February 18, 2020; revised February 25, 2020; accepted February 26, 2020; available online February $29,2020$. 
it is applied to determine the fracture reoriented distance in refracturing treatment (Warpinski et al., 1982; Dahi-Taleghani and Olson, 2011). Many researches have been done on stress field change after initial fracturing to verify the exist of fracture reorientation. Two contributors for stress reorientation are then presented: mechanical and poroelastic effects. The mechanical effect results from the opening of a propping fracture and the poroelastic effect results from pore pressure change while producing underground liquid. This theory was applied and two dimensionless parameters were presented to identify if fracture reorientation happens in refracturing treatment (Roussel and Sharma, 2013). Meanwhile, fracture reorientation can be induced by right fracturing techniques and methods (Ishida et al., 2019). It is found that perforation is an important factor to determine the direction of reorientation, perforation orientation affects the propagation reorientation in refracturing, and the shape of new fracture is affected by perforation orientation and differential stress at the same time (Zhang et al., 2008; Zhang and Chen, 2010; Guo et al., 2018). With literature reviews, some researchers worked on fracture reorientation and production analysis after refracturing (Zhang and Chen, 2009a, 2009b). Numerical and analytical models are built to calculate stress field and predict production after refracturing treatment. Factors influenced the production after refracturing treatment are analyzed, and it is identified that production will be increased by clearly analyzing the processes of fracturing treatment and production. Many of the former presented models are not suitable for predicting production of complicated fractures, especially in wells that fracture initiates and propagates at the direction different with the initial one (Reeves et al., 1999).

Many researchers have done excellent work to promote the development of refracturing technology (Bratov, 2018; Teng et al., 2019). Most researches are emphasized on the mechanics of enhanced oil recovery in refracturing, stresses analysis before refracturing and fractures propagation determination after refracturing. However, not enough detailed researches are published on evaluating potential of enhanced oil recovery in refracturing design, especially potential at different angles of the reoriented fractures. In this paper, enhanced oil recovery potential of the reoriented fractures at different angles is discussed based on the actual field data and influenced factors will be analyzed. Optimal designs of induced fracture reorientation will be proposed for field engineers.

\section{Discussion of fracture reorientation}

\subsection{Basic theory of fracture reorientation}

Fractures created in refracturing treatment may differ with the original azimuth and dip angle under some conditions, which is identified as fracture reorientation. The two main reasons for this are: propped initial fracture causes stress filed alternation around the fracture, and pore pressure change due to underground liquid production alters the initial stress field around the fracture, which are identified as mechanical effect and poroelastic effect, respectively. As shown in Fig. 1 (Lolon et al., 2008; Zhang and Chen, 2010), stress reversal caused by mechanical effect can be explained by the increase of both minimum and maximum horizontal stress due to the existing of propped fracture. However, it is obviously that stress at the direction perpendicular to the fracture increases more than that at the direction parallel to the fracture. At the original stress field, maximum horizontal stress is parallel to the initial fracture, but if the stress differential between the maximum and minimum horizontal stress is small enough and the stress increase at the direction of minimum horizontal stress is more than that at the direction of maximum horizontal stress, the minimum horizontal stress will exceed the maximum horizontal stress

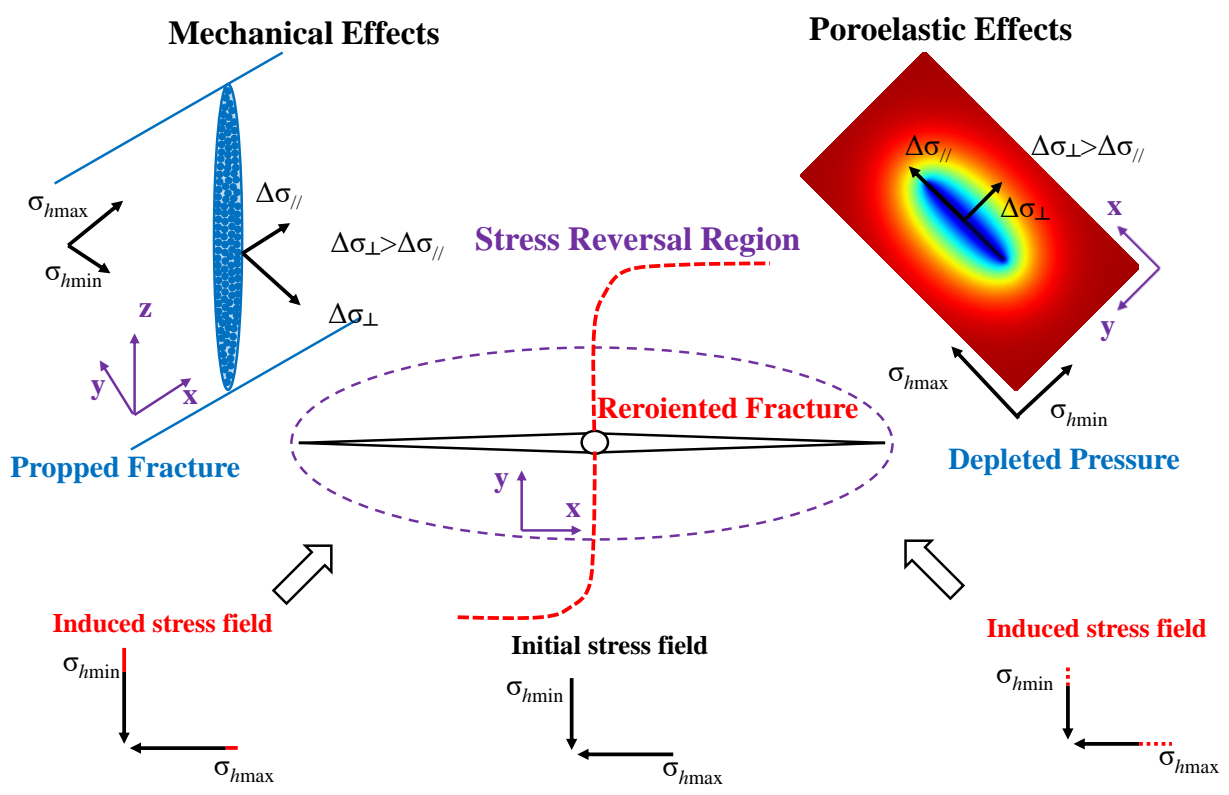

Fig. 1. Stress reversal caused by mechanical and poroelastic effects. 
which will cause that direction of horizontal stresses reverse at the angle of $90^{\circ}$ around the fracture that is called stress reversal region. Similarly, stress reversal caused by poroelastic effect can be explained that pore pressure drops more at the direction parallel to the fracture than that perpendicular to the fracture with underground liquid produced, which will lead to decrease of maximum horizontal stress faster than that of minimum horizontal stress. Finally, the minimum horizontal stress will exceed the maximum horizontal stress. Stress alternation can be induced by both mechanical effect and poroelastic effect, and stress reversal region will exist more easily especially with small stress differential between initial maximum and minimum horizontal stress.

As shown in Fig. 2, because the direction of the maximum horizontal stress is oriented by $90^{\circ}$ around the fracture, fracture created in refracturing will initiate at the direction perpendicular to the initial fracture and propagate to the isotropic point where the maximum horizontal stress equals to the minimum horizontal stress. After that, fracture will change direction gradually to the direction of the initial fracture because direction of stresses won't change at far field.

\subsection{Feasibility analysis of fracture reorientation}

\subsubsection{Criteria of fracture reorientation}

Normally, it is difficult to evaluate or predict whether fracture will reorient in refracturing treatment because it needs huge amounts of work in numerical simulation as well as physical simulation. However, there is still some excellent works from researchers provide simple and operable methods for usage in fields. Here, two dimensionless criteria (Zhang and Chen, 2010) are discussed and applied in actual field samples. The two criteria can reveal mechanical effect and poroelastic effect to a certain extent and help to identify the possibility of fracture reorientation.

The first criterion is named as mechanical stress reorientation number, expressed as Eq. (1), which is defined as the ratio of the in-situ stress contrast and the net closing pressure of a propped fracture. The second criterion is named as poroelastic stress reorientation number, which is expressed as Eq. (2) and defined as the ratio of the in-situ stress contrast and the stress contrast generated by the pore pressure gradients.

$$
\begin{gathered}
\prod_{\text {mech }}=\frac{\sigma_{h \max }-\sigma_{h \min }}{P_{c}-\sigma_{h \min }}=\frac{\Delta \sigma_{h}}{P_{n e t}} \\
\prod_{\text {pore }}=\frac{\sigma_{h \max }-\sigma_{h \min }}{\sigma_{*}}=\frac{\Delta \sigma_{h}}{\frac{\alpha(1-2 \gamma)}{1-\gamma}\left(P_{R i}-P_{w f}\right)}
\end{gathered}
$$

where $\prod_{\text {mech }}$ is the mechanical stress reorientation number; $\Pi_{\text {pore }}$ is poroelastic stress reorientation number; $\sigma_{h \max }, \sigma_{h \min }$ is maximum and minimum horizontal stress, $\mathrm{MPa} ; \Delta \sigma_{h}$ is horizontal stress contrast, $\mathrm{MPa} ; \sigma_{*}$ is stress contrast generated by pore pressure gradients, $\mathrm{MPa} ; P_{R i}$ is initial reservoir pressure, $\mathrm{MPa} ; P_{w f}$ is bottomhole pressure, MPa; $\gamma$ is Poisson's ratio; $\alpha$ is Biot's constant; and $P_{n e t}=P_{c}-\sigma_{h \text { min }}$ can be expressed as Eq. (3) which is defined as net fracture closure pressure, MPa.

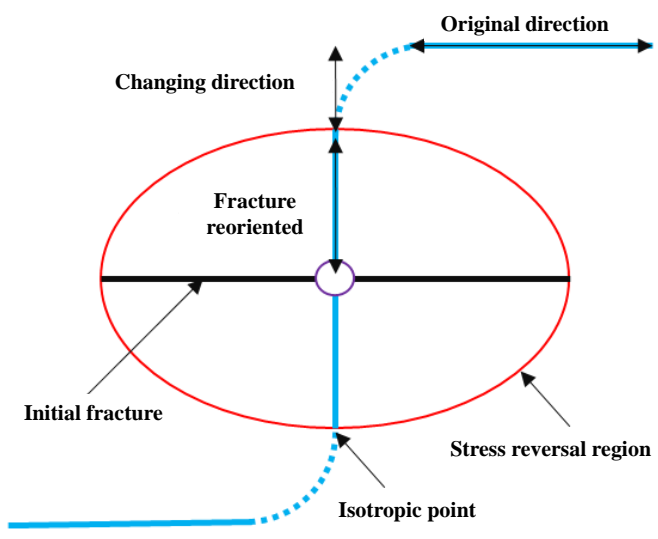

Fig. 2. Geometry of stress reversal region and refracture propagation direction.

$$
P_{n e t}=\frac{E W_{f}}{2\left(1-\gamma^{2}\right) h}
$$

where $E$ is Young's modulus, $\mathrm{MPa} ; h$ is formation thickness, $\mathrm{m} ; W_{f}$ is fracture width, $\mathrm{m}$.

These two criteria help to quantify the potential for the propagation of orthogonal refracturing in a given field. Also, the possible value of stress reorientation is identified as below 0.1 for both criteria.

\subsubsection{Fracture reorientation of field sample}

The criteria above are used to quantify the potential for fracture reorientation by applying data of actual oilfield. All data is obtained at 4 years after wells opening, and about 200 wells of the target reservoir are summarized with the two criteria calculated as shown as Figs. 3 and 4.

By comparing the two stress reorientation numbers, it can be indicated that poroelastic stress reorientation numbers are all above 0.1 which means that it is difficult to induce stress reversal by porosity drop around initial fracture. However, it doesn't mean that poroelastic effect won't lead to fracture reorientation in this reservoir, because the producing wells are just put into production for 4 years, when reservoir pressure and pore pressure are still not so depleted for inducing stress reversal. Meanwhile, it shows that mechanical stress reorientation numbers of some wells are less than 0.1 , which

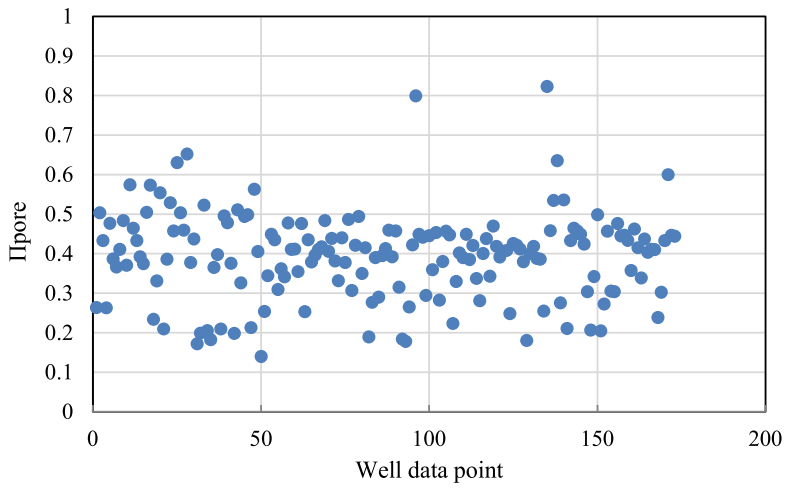

Fig. 3. Distribution of mechanical stress reorientation numbers. 


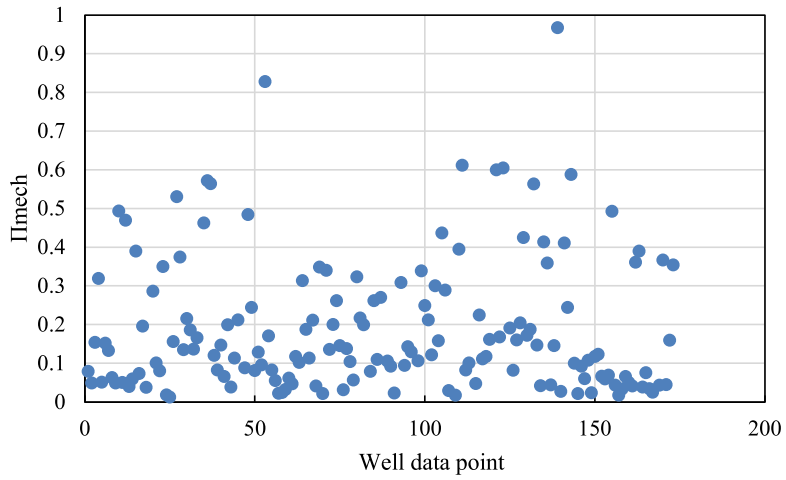

Fig. 4. Distribution of poroelastic stress reorientation numbers.

means possible fracture reorientation in refracturing treatment and indicates that mechanical effect may be the dominant effect for reorientation in this reservoir.

\section{Numerical simulation of fracture reorientation and refracturing}

\subsection{Basic model and parameters}

Actual data of field wells are collected for numerical simulation, and targeted field is a typical low permeability sandstone reservoir with rhombus inverted nine spot well pattern. In order to focus well interference on the researched wells, trick is played in choosing well for numerical simulation, as shown in Fig. 5. P3 is an edge well and P5 is a corner well, both of which are target wells for detailed research. All wells will be fractured before opening, while the two target wells will be refractured after 4 years separately to evaluate the potential of enhanced oil recovery. Size of model is 1000 $\mathrm{m} \times 600 \mathrm{~m} \times 6 \mathrm{~m}$, and number of grids is $100 \times 60 \times 6$.

After analyzing the initial stress field, direction of the maximum horizontal well is $\mathrm{NE}^{\circ} 7^{\circ}$. So the grids of the numerical model are rotated to make sure that the maximum horizontal stress is parallel to the $\mathrm{X}$ axis. Other basic parameters are shown as Table 1.

Relative permeability curve applied in the numerical model is shown as Fig. 6.
Thus, dynamic data can be calculated by the established numerical simulation model, and prediction of producing data of each well can be obtained every month. Based on the modeling results, some detailed discussion will be conducted in next sections.

Table 1. Basic model parameters.

\begin{tabular}{lll}
\hline Parameter & Unit & Value \\
\hline Porous media density & $\mathrm{kg} / \mathrm{m}^{3}$ & 2500 \\
Dead oil density & $\mathrm{kg} / \mathrm{m}^{3}$ & 851 \\
Average permeability & $\mu \mathrm{m}^{2}$ & 0.002 \\
Average effective porosity & - & 0.125 \\
Initial reservoir pressure & $\mathrm{MPa}$ & 10 \\
Saturated pressure & $\mathrm{MPa}$ & 6.85 \\
Oil formation volume factor & - & 1.206 \\
Bottomhole pressure & $\mathrm{MPa}$ & 5 \\
Underground oil viscosity & $\mathrm{mPa} \cdot \mathrm{s}$ & 2.24 \\
Reservoir depth & $\mathrm{m}$ & 1580 \\
Liquid compressibility factor & $\mathrm{MPa}^{-1}$ & $1.05 \times 10^{-4}$ \\
Porous media compressibility factor & $\mathrm{MPa}^{-1}$ & $2.0 \times 10^{-4}$ \\
Formation water compressibility factor & $\mathrm{MPa}^{-1}$ & $1.0 \times 10^{-4}$ \\
\hline
\end{tabular}

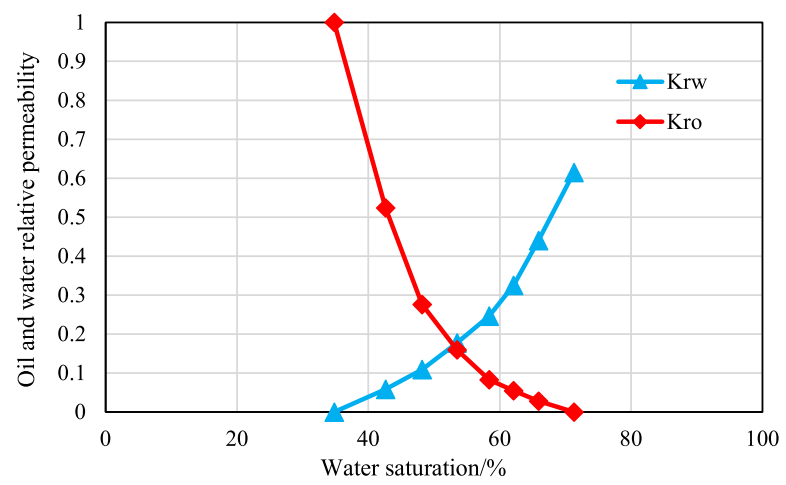

Fig. 6. Relative permeability curve.

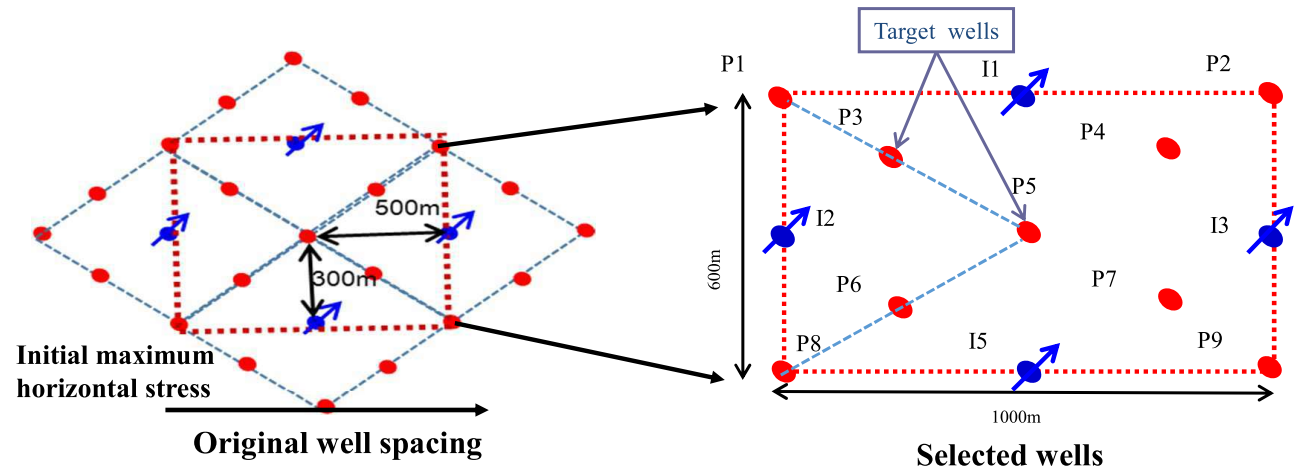

Fig. 5. Target wells for reorientation design and potential evaluation. 


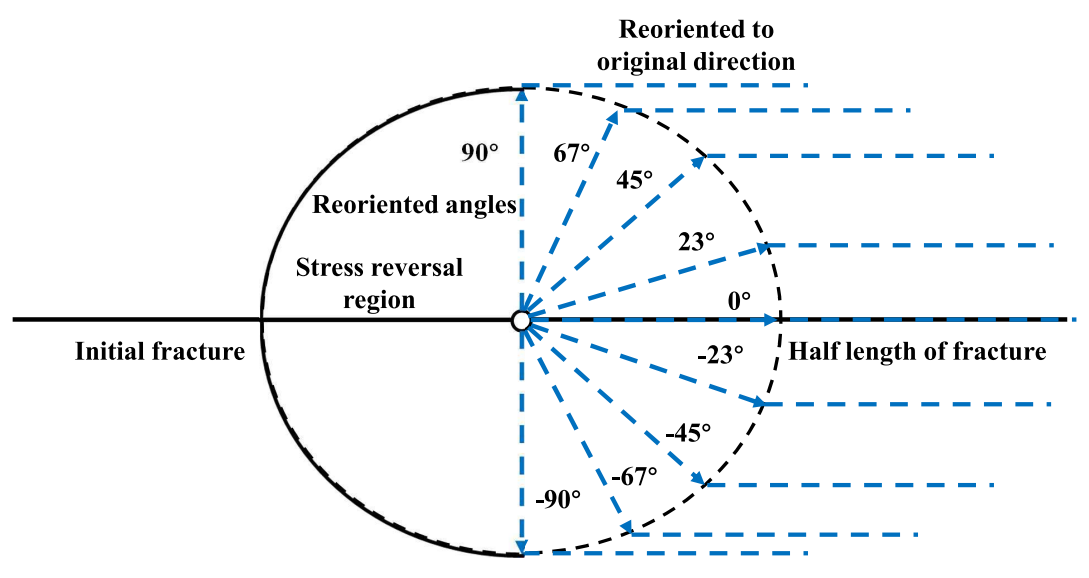

Fig. 8. Geometry of stress reversal region and fracture propagation.

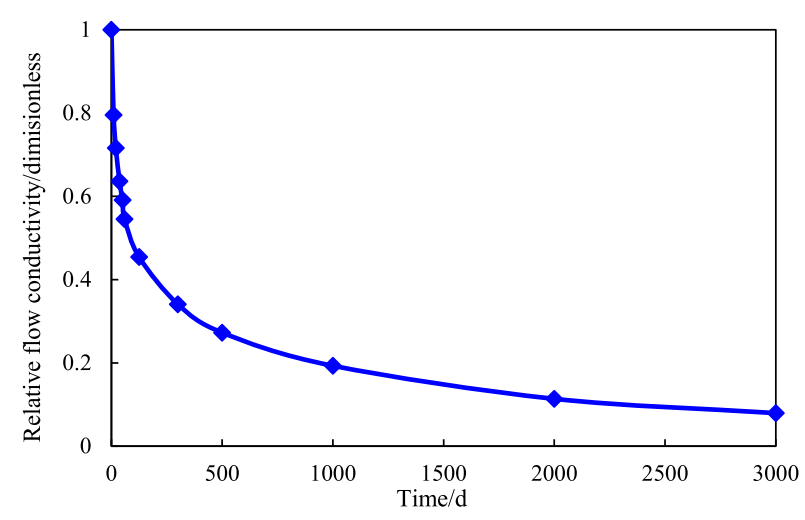

Fig. 7. Relationship of relative flow conductivity of fracture versus time.

\subsection{Simulation of reoriented fractures}

Initial fractures are simulated with the method of local grid refinement with fracture half-length of $150 \mathrm{~m}$ and initial fracture conductivity of $150 \times 10^{-3} \mu \mathrm{m}^{2} \cdot \mathrm{m}$. And since flow capacity will decrease with time, flow conductivity is set to change with time in the numerical simulation model. Eq. (4) shows the relationship of relative flow conductivity of fracture versus time and can be plot as Fig. 7 .

$$
K_{f} w_{f}=K_{f 0} w_{0}[1-0.27 \lg (t+1)]
$$

where $K_{f 0} w_{0}$ is the initial flow conductivity, $10^{-3} \mu \mathrm{m}^{3} ; t$ is time, day.

After developing for 4 years, refracturing treatment will be completed to the targeted researching corner well and edge well. As illustrated above, there is high possibility that fracture will be reoriented after refracturing, and geometry of reoriented fractures is simplified as show in Fig. 8. The stress reversal region is assumed as a circle instead of an ellipse, fractures initiate from the wellbore perpendicular to the initial fracture and propagate directly to the isotropic point, and then the process that fracture reorients to the initial fracture is eliminated due to the its short propagation path. All the simplifications are based on that fracture propagation during

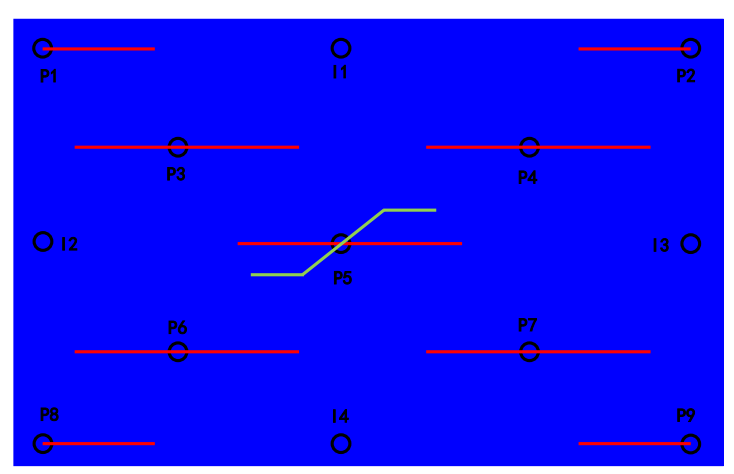

Fig. 9. Schematic of fracture in simulation (corner well $45^{\circ}$ ).

refracturing is not the priority thing researched in this paper, and the most important thing is to figure out the potential of enhanced oil recovery with reoriented fractures of different angles. As discussed by Zhang and Chen (2010), fractures can be reoriented to fixed direction as the operators wished which is verified and simulated in physical experiments, and angles of oriented fractures designed in this paper are set as some fixed values as shown in Fig. 8.

Simulation of reoriented fractures in the model is shown as Fig. 9. Take the corner well with fracture reorientation angle of $45^{\circ}$ as the sample. And it is assumed that fractures will restore flow conductivity to the initial level, and then it decreases following the relationship of relative flow conductivity of fracture versus time.

\section{Analysis of residual oil distribution in refrac- turing}

\subsection{Residual oil distribution of corner well}

Fig. 10 shows distribution of residual oil saturation under different conditions of the target corner well. Fig. 10(a) is distribution of residual oil saturation of the $4^{\text {th }}$ year, and no refracturing treatment is completed yet. Fig. 10(b) shows distribution of residual oil saturation of the $10^{\text {th }}$ year with no refracturing treatment. Fig. 10(c) shows distribution of residual 


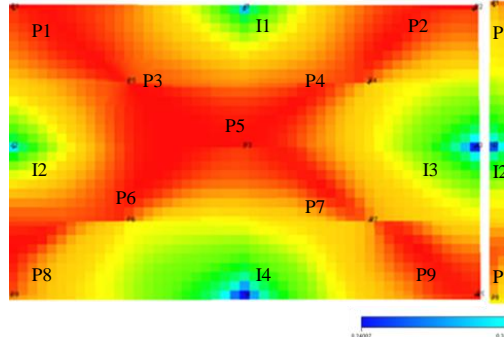

(a)

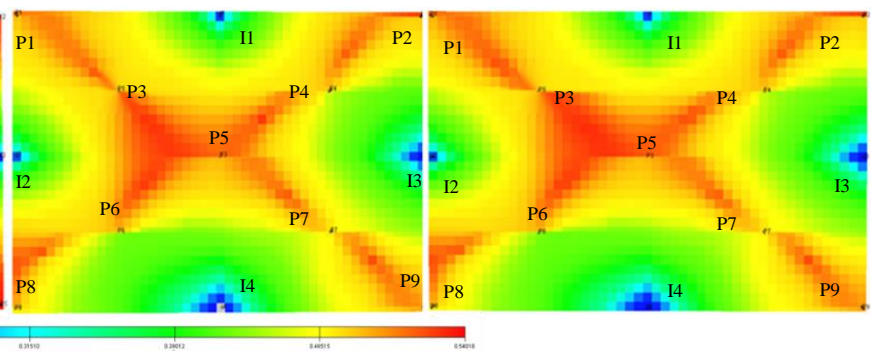

(b)

(c)

Fig. 10. Residual oil saturation of the corner well, (a) $4^{\text {th }}$ year before refracturing, (b) the $10^{\text {th }}$ year without refracturing, (c) the $10^{\text {th }}$ year, refracturing at the $4^{\text {th }}$ year without fracture reorientation.

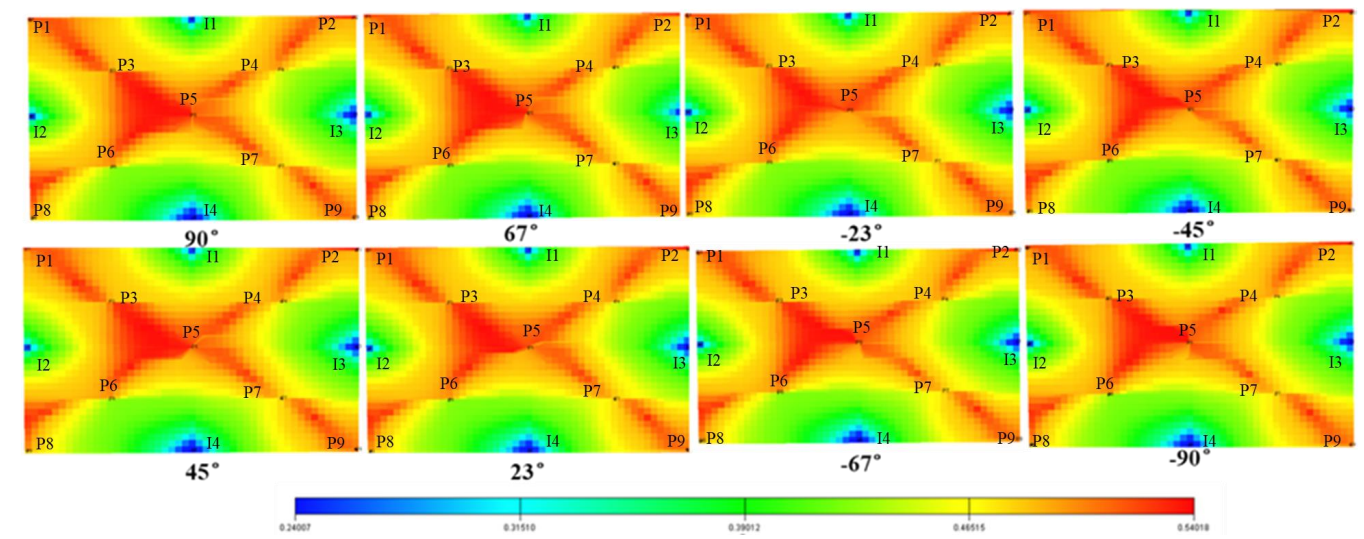

Fig. 11. Oil saturation with different angles of fracture reorientation after refracturing (corner well).

oil saturation of the $10^{\text {th }}$ year with refracturing treatment completed at the $4^{\text {th }}$ producing year with no fracture reorientation in the refracturing treatment.

It is obviously that residual oil saturation is much lower at the $10^{\text {th }}$ year than that at the $4^{\text {th }}$ year development as shown in Fig. 10(a) and Fig. 10(b). However, there seems to be no big difference of residual oil saturation between Fig. 10(b) and Fig. 10(c), and restore the conductivity of the initial fracture can increase the production while the enhancement is limited because there is not enough residual oil around the initial fracture and pore pressure drops too much, which all determine that potential of enhanced oil recovery of reopening initial fracture is lower than fracture reorientation. Meanwhile, most of the residual oil is remained at all four corner point of the drainage area of the corner well, to enhance the oil recovery, to motivate the residual oil and there is the most effective way.

Refracturing treatment is implemented after producing with the initial fracture for 4 years when fracture conductivity of the initial fracture has already dropped to less than $20 \%$ of the original value or even worse of losing all the conductivity. Fractures initiated in the refracturing treatment are design with different angles of reorientation including $90^{\circ}, 67^{\circ}, 45^{\circ}, 23^{\circ}$, $-23^{\circ},-45^{\circ},-67^{\circ},-90^{\circ}$ as illustrated in Fig. 8. Also, $0^{\circ}$ with refracturing treatment but no fracture orientation was discussed above. Residual oil saturation of the target corner well with different angles of fracture reorientation after refracturing is shown as Fig. 11. Distribution of residual oil with different angles is obviously different which indicates that regions with more residual oil can be intersected by fracture reorientation.

\subsection{Residual oil distribution of edge well}

Same as the corner well, distribution of residual oil saturation under different conditions of the target edge well is also depicted as shown in Fig. 12. Similarly, Fig. 12(a) is for the $4^{\text {th }}$ year with no refracturing treatment, Fig. 12(b) is for the $10^{\text {th }}$ year with no refracturing treatment, and Fig. 12(c) is for the $10^{\text {th }}$ year with refracturing treatment completed at the $4^{\text {th }}$ producing year and no fracture reorientation in the refracturing treatment.

Similarly, fractures are design with different angles of reorientation including $90^{\circ}, 67^{\circ}, 45^{\circ}, 23^{\circ},-23^{\circ},-45^{\circ},-67^{\circ}$, $-90^{\circ}$. Residual oil saturation of the target edge well with different angles of fracture reorientation after refracturing is shown as Fig. 13. Influence of fracture angles of edge well seems to be larger than that of the corner well. Also, it is shown that region with rich residual oil of edge well is narrower than that of the corner well because wells at different positons are varied in drainage areas.

\section{Enhanced oil recovery analysis of fracture reorientation}

\subsection{Enhanced oil recovery of corner well}




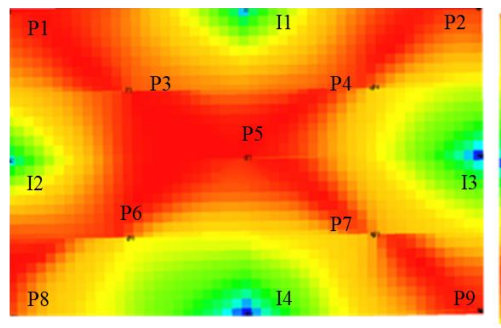

(a)

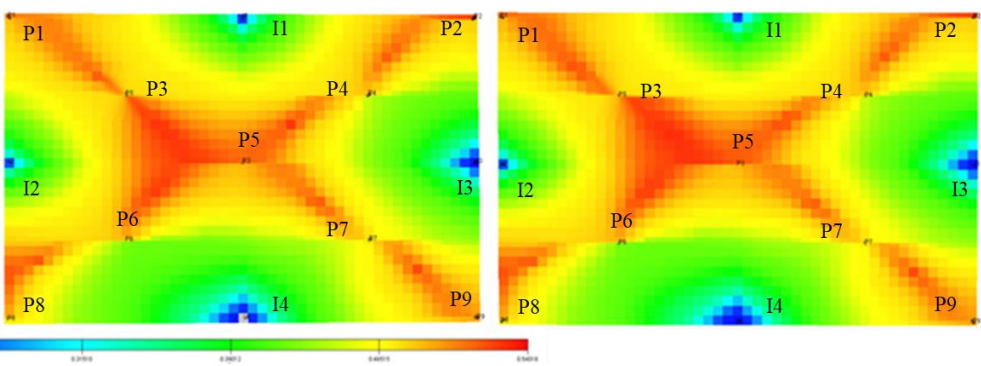

(b)

(c)

Fig. 12. Residual saturation of the edge well, (a) the $4^{\text {th }}$ year before refracturing, (b) the $10^{\text {th }}$ year without refracturing, (c) the $10^{\text {th }}$ year, refracturing at the $4^{\text {th }} \mathrm{h}$ year without fracture reorientation.
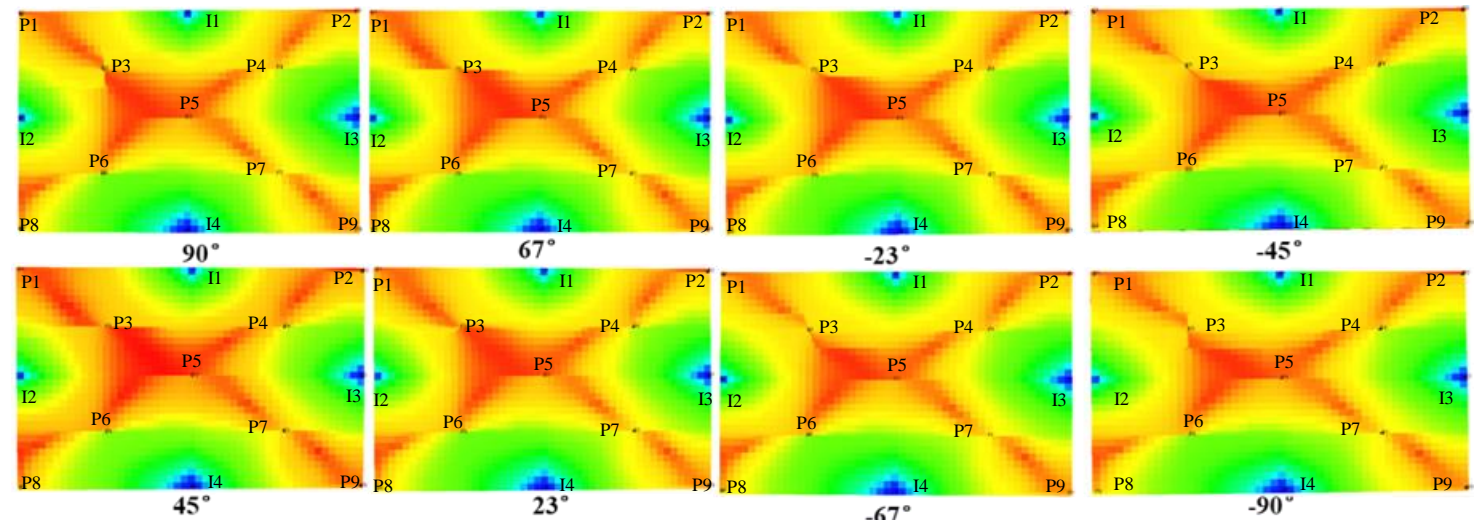

$-67^{\circ}$

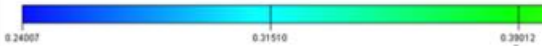

Fig. 13. Oil saturation with different angels of fracture reorientation after refracturing (edge well).

Table 2. Cumulative oil production of different refracture propagation direction (corner well).

\begin{tabular}{ll}
\hline Angles & Accumulative oil production $/ 10^{4} \mathrm{~m}^{3}$ \\
\hline$-90^{\circ}$ & 1.363 \\
$-67^{\circ}$ & 1.328 \\
$-45^{\circ}$ & 1.308 \\
$-23^{\circ}$ & 1.364 \\
$0^{\circ}$ & 1.225 \\
$23^{\circ}$ & 1.352 \\
$45^{\circ}$ & 1.281 \\
$67^{\circ}$ & 1.295 \\
$90^{\circ}$ & 1.331 \\
No refracturing & 0.949 \\
\hline
\end{tabular}

Cumulative oil production of target corner wells with different angles of fracture reorientation is obtained as shown in Table 2.

Based on analysis of residual oil distribution of corner wells, residual oil motivated in the later 6 years after refracturing differs with different reoriented angles. As shown in Fig. 14 , accumulative oil production with different angles of frac-

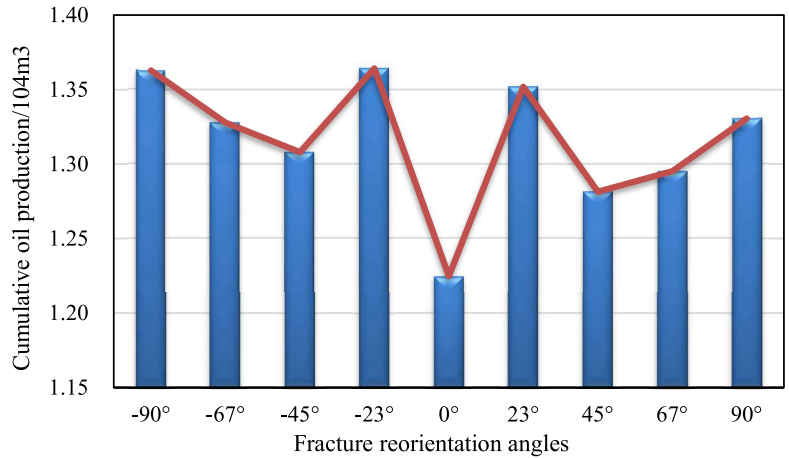

Fig. 14. Cumulative oil production of different refracture propagation direction (corner well).

ture are obviously different, which are higher at the angle of positive and negative $23^{\circ}$, as well as positive and negative $90^{\circ}$. Also, it is obviously that there is some kind of relationship among angles in positive and negative angles, both of which have the highest production with angle of $23^{\circ}$, then $90^{\circ}, 67^{\circ}$ and with $45^{\circ}$ at the lowest. However, production of positive angles is higher than the same angle at the positive angle which is caused by the heterogeneity of the reservoir properties. Properties such as permeability and porosity at the upper part of the model are better than those of the lower part, which is 
Table 3. Cumulative oil production of different refracture propagation direction (edge well).

\begin{tabular}{ll}
\hline Angles & Accumulative oil production $/ 10^{4} \mathrm{~m}^{3}$ \\
\hline$-90^{\circ}$ & 1.147 \\
$-67^{\circ}$ & 1.132 \\
$-45^{\circ}$ & 1.109 \\
$-23^{\circ}$ & 1.121 \\
$0^{\circ}$ & 1.013 \\
$23^{\circ}$ & 1.074 \\
$45^{\circ}$ & 1.035 \\
$67^{\circ}$ & 1.048 \\
$90^{\circ}$ & 1.086 \\
No refracturing & 0.847 \\
\hline
\end{tabular}

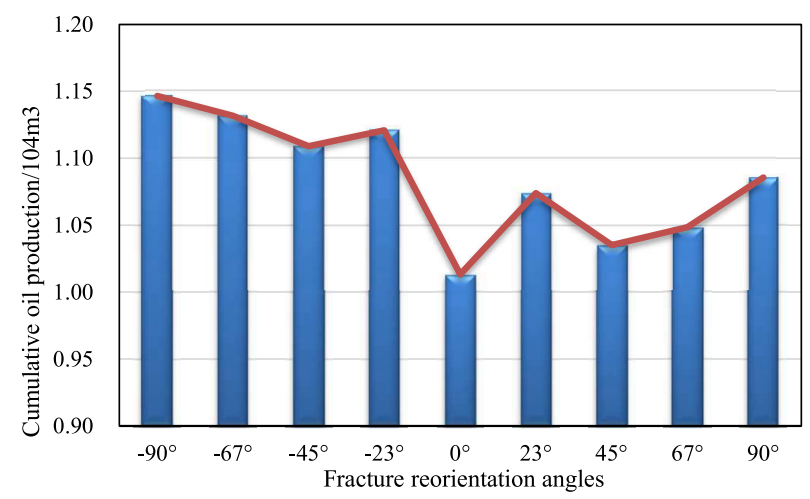

Fig. 15. Cumulative oil production of different refracture propagation direction(edge well).

shown as more residual oil produced at the early term of development. So, more residual oil will be produced because of fracture reoriented to those regions at lower part after refracturing.

\subsection{Enhanced oil recovery of edge well}

Cumulative oil production of target edger wells with different angles of fracture reorientation is obtained as shown in Table 3 and plotted in Fig. 15.

Based on analysis of residual oil distribution of edge wells, residual oil motivated in the later 6 years after refracturing differs with different reoriented angles. As shown in Fig. 16, accumulative oil production with different angles of fracture is obviously different, but production is higher at the positive angle than that at the negative angles different with that of corner well. The reason of the difference between corner well and edge well is obviously due to the well position in the well pattern. Same as the corner well, there is some kind of relationship among angles in positive and negative angles, both of which have the high production with angle of $90^{\circ}$ and $23^{\circ}$, then $67^{\circ}$ and $45^{\circ}$, and also with $45^{\circ}$ at the lowest.
Results show that for corner wells, the optimal angles for fracture reorientation are positive and negative $23^{\circ}$, while for edge well, the optimal angles are positive and negative $90^{\circ}$.

As discussed above, well pattern, well position, fracture reoriented angle and reservoir properties are all important factors for evaluating potential of refracturing.

\section{Conclusions}

Mechanisms of fracture reorientation is discussed and feasibility of fracture reorientation can be predicted by the criteria presented. Based on the numerical simulation results, residual oil distribution with reoriented fractures is discussed and the estimated ultimate recovery is predicted.

(1) Mechanical effect and poroelastic effect are the two main factors for stress field change which lead to formation of stress reversal region and initiation of fracture reorientation.

(2) The two dimensionless criteria can reveal mechanical effect and poroelastic effect and help to identify the possibility of fracture reorientation. Reorientation is easy to happen in wells with either small mechanical stress reorientation number or poroelastic stress reorientation number.

(3) Distribution of residual oil with different fracture angles is obviously different and there is also difference for wells at different position in the well pattern, like corner well and edge well.

(4) Potential of enhancement is significantly different with angles of fractures which is shown as: cumulative produced oil of the corner well is symmetrical around the angle of $0^{\circ}$ from positive and negative for both corner well and edge well. The optimal angles for fracture reorientation are positive and negative $23^{\circ}$, while for edge well, the optimal angles are positive and negative $90^{\circ}$.

(5) Well pattern, well position, fracture reoriented angle and reservoir properties are all important factors for evaluating potential of refracturing which should be considered before restimulation design.

\section{Acknowledgement}

This study was supported by the Major National Science and Technology Project (2017ZX05009-001, 2017ZX05069, 2017ZX05072).

\section{Conflict of interest}

The authors declare no competing interest.

Open Access This article is distributed under the terms and conditions of the Creative Commons Attribution (CC BY-NC-ND) license, which permits unrestricted use, distribution, and reproduction in any medium, provided the original work is properly cited.

\section{References}

Barree, R.D., Miskimins, J.L., Svatek, K.J. Reservoir and completion considerations for the refracturing of horizontal wells. SPE Prod. Oper. 2017, 33(1): 1-11.

Berchenko, I., Detournay, E. Deviation of hydraulic fractures through poroelastic stress changes induced by fluid 
injection and pumping. Int. J. Rock Mech. Min. Sci. 1997, 34(6): 1009-1019.

Bratov, V. Numerical models for hydraulic refracturing on vertical oil wells. Int. J. Eng. Technol. 2018, 7(4.26): 279-284.

Dahi-Taleghani, A., Olson, J.E. Numerical modeling of multistranded hydraulic fracture propagation: Accounting for the interaction between induced and natural fractures. SPE J. 2011, 16(3): 575-581.

Elbel, J.L., Mack, M.G. Refracturing: Observations and theories. Paper SPE 25464 Presented at SPE Production Operations Symposium, Oklahoma City, Oklahoma, 2123 March, 1993.

Guo, T., Gong, F., Qu, Z., et al. Study on fracture initiation mechanisms of hydraulic refracturing guided by directional boreholes. J. Energ. Resour. Technol. 2018, 140(8): 084901.

Hubbert, M.K., Willis, D.G. Mechanics of hydraulic fracturing. Trans. AIME 1957, 210: 153-168.

Ishida, T., Fujito, W., Yamashita, H., et al. Crack expansion and fracturing mode of hydraulic refracturing from acoustic emission monitoring in a small-scale field experiment. Rock Mech. Rock Eng. 2019, 52(2): 543553.

Lolon, E.P., Mayrhofer, M.J., Garcia, I. Integrated fracture and production modeling study in the lower cotton valley sands, Northern Louisiana. Paper SPE 115467 Presented at SPE Annual Technical Conference and Exhibition, Denver, Colorado, USA, 21-24 September, 2008.

Preiksaitis, M., Baig, A., Bowman-Young, S., et al. Identifying re-stimulation effectiveness by utilizing microseismic attributes. Paper SPE 2461172 Presented at the Unconventional Resources Technology Conference, San Antonio, Texas, 1-3 August, 2016.

Reeves, S.R., Hill, D.G., Hopkins, C.W., et al. Restimulation technology for tight gas sand wells. Paper SPE 56482 Presented at SPE Annual Technical Conference and Exhibition held in Houston, Texas, USA, 3-6 October, 1999.

Roussel, N.P., Sharma, M.M. Quantifying transient effects in altered-stress refracturing of vertical wells. SPE J. 2010, 15(3): 770-782.

Roussel, N.P., Sharma, M.M. Optimizing fracture spacing and sequencing in horizontal-well fracturing. SPE Prod. Oper. 2011, 26(2): 173-184.
Roussel, N.P., Sharma, M.M. Role of stress reorientation in the success of refracture treatments in tight gas sands. SPE Prod. Oper. 2012, 27(4): 346-355.

Roussel, N.P., Sharma, M.M. Selecting candidate wells for refracturing using production data. SPE Prod. Oper. 2013, 28(1): 36-45.

Sallee, W.L., Rugg, F.E. Artificial formation fracturing in Southern Oklahoma and North-Central Texas. AAPG Bull. 1953, 37(11): 2539-2550.

Shah, M., Subhash S., Anirbid S. A comprehensive overview on recent developments in refracturing technique for shale gas reservoirs. J. Nat. Gas. Sci. Eng. 2017, 46: 350-364.

Siebrits, E., Elbel, J.L., Detournay, E., et al. Parameters affecting azimuth and length of a secondary fracture during a refracture treatment. Paper SPE 48928 Presented at SPE Annual Technical Conference and Exhibition, New Orleans, USA, 27-30 September, 1998.

Teng, B., Li, H.A. A semi-analytical model for characterizing transient flow behavior of reoriented refractures. J. Petrol. Sci. Eng. 2019, 177: 921-940.

Vincent, M. Restimulation of unconventional reservoirs: When are refracs beneficial. J. Can. Petrol. Technol. 2011, 50(5): 36-52.

Warpinski, N.R., Branagan, P.T. Altered stress fracturing. J. Pet. Tech. 1989, 41(9): 990-997.

Warpinski, N.R., Clark, J.A., Schmidt, R.A., et al. Laboratory investigation on the effect of in-situ stresses on hydraulic fracture containment. Soc. Petrol. Eng. J. 1982, 22(3): 333-340.

Zhang, G., Chen, M. Study of the optimal timing for refracturing. Petrol. Sci. Technol. 2009a, 27(10): 969983.

Zhang, G., Chen, M. Relationship between production and initiation location of new fractures in re-fractured well. Journal of Liaoning Technical University (Natural Science) 2009b, 28(3): 407-409. (in Chinese)

Zhang, G., Chen, M. Dynamic fracture propagation in hydraulic re-fracturing. J. Petrol. Sci. Eng. 2010, 70(3): 266-272.

Zhang, G., Chen, M., Yao, F. Study on optimal refracturing timing in anisotropic formation and its influencing factors. Acta Petrolei Sinica 2008, 29: 885-888. (in Chinese) 